Article

\title{
Numerical Investigation on the Flow and Heat Transfer Characteristics of Supercritical Liquefied Natural Gas in an Airfoil Fin Printed Circuit Heat Exchanger
}

\author{
Zhongchao Zhao *, Kai Zhao, Dandan Jia, Pengpeng Jiang and Rendong Shen \\ School of Energy and Power, Jiangsu University of Science and Technology, Zhenjiang 210000, China; \\ kzhaojust@163.com (K.Z.); 18796083725@163.com (D.J.); jppwork@163.com (P.J.); shenrendong@163.com (R.S.) \\ * Correspondence: zhongchaozhao@just.edu.cn; Tel.: +86-0511-8449-3050
}

Received: 25 July 2017; Accepted: 1 November 2017; Published: 10 November 2017

\begin{abstract}
As a new kind of highly compact and efficient micro-channel heat exchanger, the printed circuit heat exchanger (PCHE) is a promising candidate satisfying the heat exchange requirements of liquefied natural gas (LNG) vaporization at low and high pressure. The effects of airfoil fin arrangement on heat transfer and flow resistance were numerically investigated using supercritical liquefied natural gas (LNG) as working fluid. The thermal properties of supercritical LNG were tested by utilizing the REFPROF software database. Numerical simulations were performed using FLUENT. The inlet temperature of supercritical LNG was $121 \mathrm{~K}$, and its pressure was $10.5 \mathrm{MPa}$. The reference mass flow rate of LNG was set as $1.22 \mathrm{~g} / \mathrm{s}$ for the vertical pitch $L_{v}=1.67 \mathrm{~mm}$ and the staggered pitch $L_{s}=0 \mathrm{~mm}$, with the Reynolds number of about 3750 . The SST k- $\omega$ model was selected and verified by comparing with the experimental data using supercritical liquid nitrogen as cold fluid. The airfoil fin PCHE had better thermal-hydraulic performance than that of the straight channel PCHE. Moreover, the airfoil fins with staggered arrangement displayed better thermal performance than that of the fins with parallel arrangement. The thermal-hydraulic performance of airfoil fin PCHE was improved with increasing $L_{S}$ and $L_{v}$. Moreover, $L_{v}$ affected the Nusselt number and pressure drop of airfoil fin PCHE more obviously. In conclusion, a sparser staggered arrangement of fins showed a better thermal-hydraulic performance in airfoil fin PCHE.
\end{abstract}

Keywords: printed circuit heat exchanger; airfoil fin; supercritical liquefied natural gas (LNG); thermal-hydraulic performance

\section{Introduction}

Owing to its high calorific value and low carbon dioxide emissions, natural gas (NG) has become the best choice for replacing traditional resources such as coal and petroleum [1,2]. Generally; NG is cooled to form liquefied natural gas (LNG), allowing it to be stored and transported over long distances. LNG is then heated and regasified into NG before being transferred into pipelines to meet the demand of users [3,4]. Efficient and reliable vaporization devices have been highlighted as critical equipment in the LNG gasification system. Four main kinds of LNG vaporizers are are commercially available: intermediate fluid vaporizers; open rack vaporizers (ORVs); super ORVs and submerged combustion vaporizers [5-7].

However, traditional LNG vaporizers cannot meet the requirements of miniaturization and high compactness in the construction of LNG gasification systems. Therefore, it is urgent to find an efficient and compact heat exchanger to replace these traditional vaporizers. Because of safety, high compactness and efficiency, printed circuit heat exchangers (PCHEs) have drawn wide attention 
in recent years [8-11]. A PCHE is a micro-channel heat exchanger manufactured by photochemical etching and diffusion bonding [12-15]. As a result, PCHEs show better heat transfer performance than those of other types of heat exchanger due to their larger heat surface area caused by the presence of many micro-channels. Nevertheless, PCHEs suffer from enhanced pressure drop. Therefore, researchers have endeavored to improve the thermal-hydraulic characteristics of PCHEs [16-23].

Four types of PCHE flow channels, i.e., straight, zigzag, S-shape, and airfoil fin have been developed so far. Mylavarapu et al. [24] experimentally tested PCHEs with straight, circular and semicircular channels at $2.7 \mathrm{MPa}$ with various Reynolds numbers. The transition from laminar flow to flow regime occurred much earlier in the semicircular channel than within the circular pipe.

Ma et al. [25] studied the pressure drop mechanism and the local heat transfer of PCHEs with zigzag channels and the effect of the inclination angle of channels on the thermal-hydraulic performance of the PCHEs under the operating conditions of a very high temperature reactor. Figley et al. [26] studied the heat transfer and pressure drop characteristics of PCHEs with zigzag channels by the aid of three-dimensional numerical simulations. Aneesh et al. [27] studied the thermal-hydraulic characteristics and properties of 3D straight channel-based PCHEs. Khan et al. [28] investigated the thermal-hydraulic characteristics and performance of PCHEs for various angles of bend $\left(\theta=0^{\circ}, 5^{\circ}, 10^{\circ}\right.$, and $\left.15^{\circ}\right)$ and different Reynolds numbers ( $R e=350,700,1400$ and 2100). As $R e$ and $\theta$ increased, the thermal hydraulic performance was boosted.

PCHEs with straight and Z-shaped channels were analyzed initially. However, many researchers have found that PCHEs with distributed fins, such as S-shaped fins and airfoil fins, have better thermal-hydraulic characteristics. Ngo et al. [29] studied a new PCHE with an S-shaped fin structure applied to a hot water supplier which uses supercritical $\mathrm{CO}_{2}$ as heat source. The new PCHE had about 3.3 times less volume, but it displayed a $37 \%$ lower pressure drop on the $\mathrm{CO}_{2}$ side and by ten times on the $\mathrm{H}_{2} \mathrm{O}$ side than an existing $1.5 \mathrm{MW} / \mathrm{m}^{3}$ hot water supplier.

Kim et al. [30] proposed an airfoil fin, making the pressure drop of the airfoil fin one-twentieth of that of zigzag channel, but their total heat transfer rates per unit volume were basically the same, to enhance the thermal hydraulic performance of PCHE. Although PCHEs have better thermal hydraulic performance than traditional heat exchangers due to the smaller hydraulic diameter of their flow channels, this also raises the pressure drop. In addition to optimizing the channel shape of PCHEs, many researchers have focused on the fluid in the flow channels [31]. Compared to traditional fluids, supercritical fluids have many advantageous characteristics as the working fluid in PCHEs, such as high density, low viscosity and high thermal conductivity [32-34].

Supercritical carbon dioxide and water have been applied in PCHEs. Kruizenga et al. [35] performed an experimental study to estimate the pressure drop and heat transfer of PCHEs in which the supercritical $\mathrm{CO}_{2}$ was selected as the working fluid. The heat transfer significantly increased when the pseudocritical temperature and critical pressure were approached.

Kim et al. [36] performed numerical investigations to study the performance of airfoil fin PCHEs in which supercritical carbon dioxide was used as the working fluid. They examined the optimal arrangement of airfoil fins with an objective function, and the arrangement had a staggered spacing of $1 \mathrm{~mm}$.

Despite the extensive studies on the thermal hydraulic performance of PCHEs using supercritical carbon dioxide and water as working fluids, the thermal-hydraulic performance of PCHEs used in an LNG vaporization system at low temperature and high pressure has rarely been reported hitherto. In this study, the numerical simulation method was used to analyze the thermal-hydraulic performance of a PCHE using supercritical LNG as the work fluid. The heat transfer and flow characteristics of supercritical LNG in a single channel of straight channel PCHE and airfoil fin PCHE were compared at different mass fluxes. To obtain the correlations between performance factors and configuration factors, pressure drop and heat transfer were replaced with dimensionless representations (Nusselt number and Euler number). The effects of airfoil fin arrangements on heat transfer and pressure drop characteristics were analyzed. Finally, an optimal design for the fin arrangement in an airfoil 
fin PCHE was suggested. The results in favour of the optimum thermal design and operation of high-performance airfoil fin PCHE.

\section{Computational Fluid Dynamic Analysis for Thermal-Hydraulic Performance}

\subsection{Thermal-Physical Properties of Supercritical LNG}

In this study, the LNG pressure was 10.5 MPa, exceeding its critical pressure ( $\mathrm{P}=4.59 \mathrm{MPa})$. As a result, LNG in the PCHE channel was in the supercritical state, whereby an obvious liquid phase and gas phase do not exist. Like other supercritical fluids, supercritical LNG also has various favorable characteristics like high density, high thermal conductivity and low viscosity. The properties including density, thermal conductivity, specific heat and viscosity were calculated by REFPROP 9.0 software (Figure 1). Meanwhile, the accuracy of the property data in the entire regime computation was validated (Figure 2). The errors were within $\pm 4 \%$, indicating the viability of this computation method. The thermal properties of supercritical LNG were calculated with the FLUENT software by defining the piecewise-linear functions of temperature (Table 1).

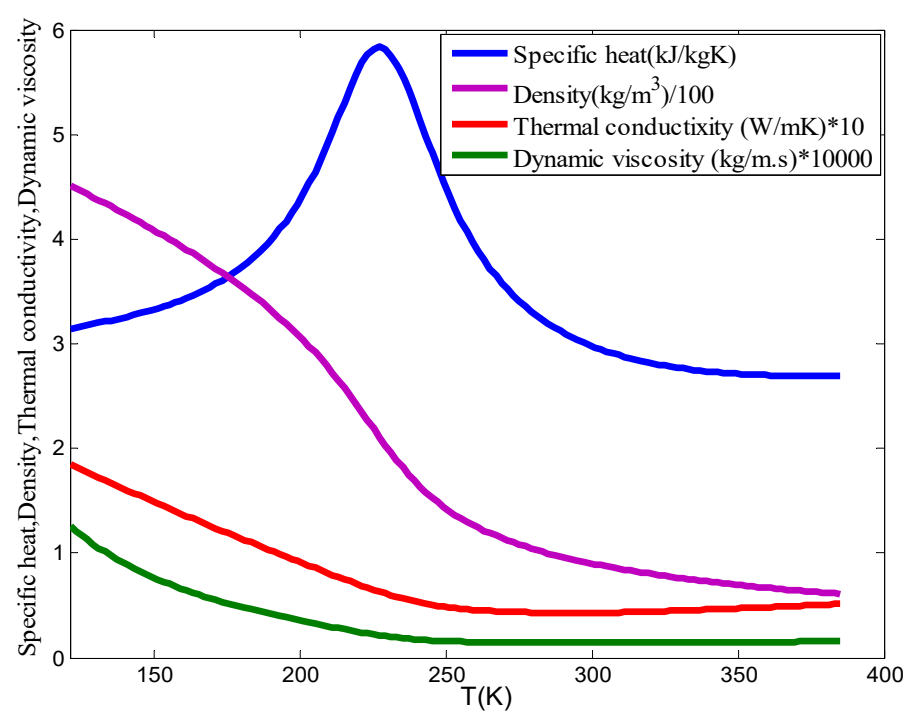

Figure 1. Thermal-physical properties of LNG at 10.5 MPa.

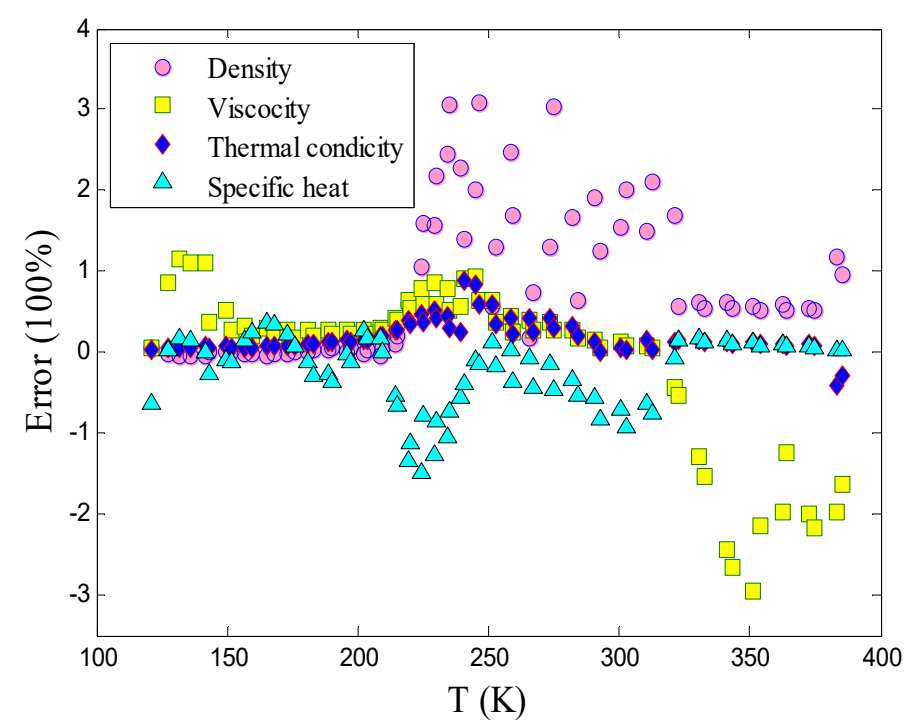

Figure 2. Error curve of linear interpolation function. 
Table 1. Property correlations of LNG at $10.5 \mathrm{Mpa}$.

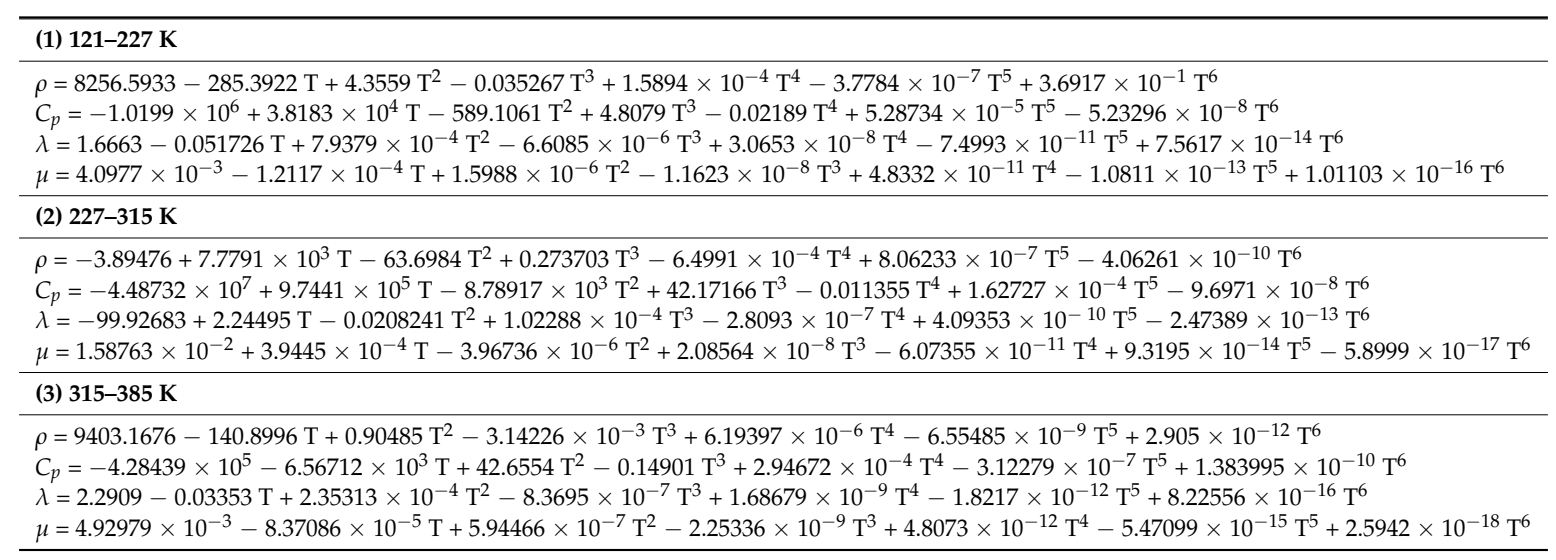

\subsection{Physical Models and Definition of Airfoil Fin Arrangement Parameters}

Generally, an airfoil fin PCHE consists of several micro-channels, with several airfoil fins in one channel. Therefore, it is extremely difficult to simulate the entire heat exchanger geometry because a powerful computer and long computation time are needed. However, as shown in Figure 3, the flow channel formed by airfoil fins is periodic in both the longitudinal direction and the transverse direction, except for the plate border in a PCHE. Therefore, considering the computing resource, forty periodic fin structures along the flow direction from the core area of heat exchanger with the length of $260 \mathrm{~mm}$ were selected firstly. The vertical pitch $L_{v}$ and staggered pitch $L_{s}$ of airfoil fins were $1.67 \mathrm{~mm}$ and $0 \mathrm{~mm}$ respectively, aiming to compare the heat transfer and flow characteristics of supercritical LNG between airfoil fin and straight channel with the same channel length and hydraulic diameter. The numerical models of straight channel and airfoil fin are shown in Figures 4 and 5, respectively.

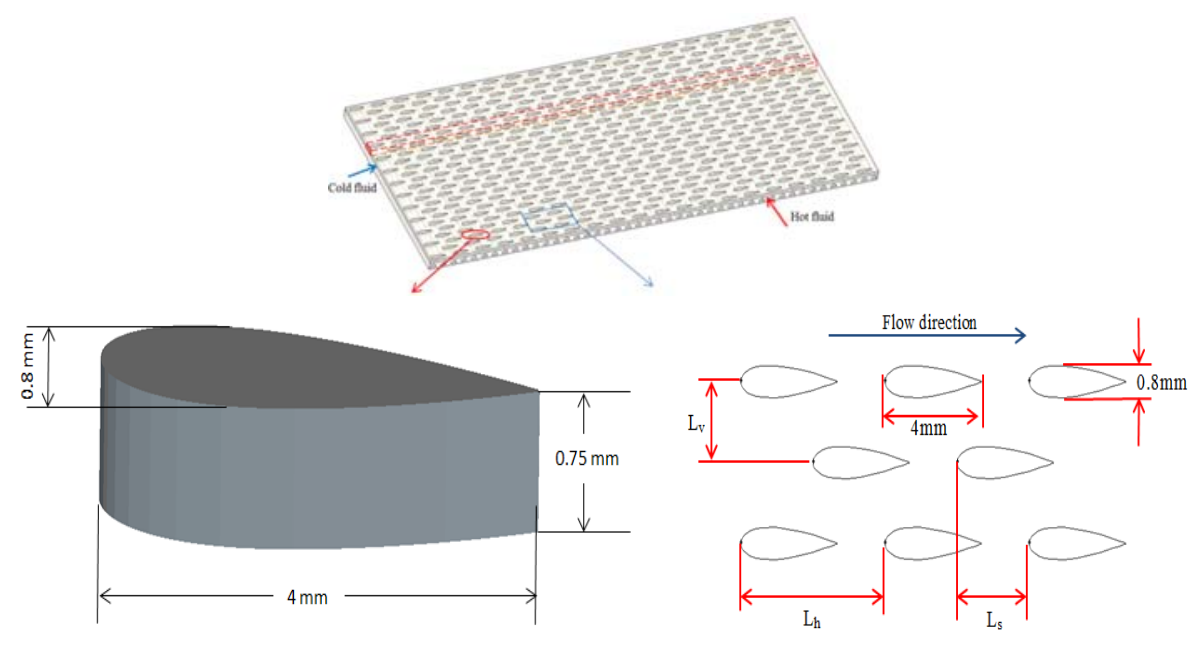

Figure 3. Schematic diagram of internal core structure of airfoil fin printed circuit heat exchanger (PCHE). 


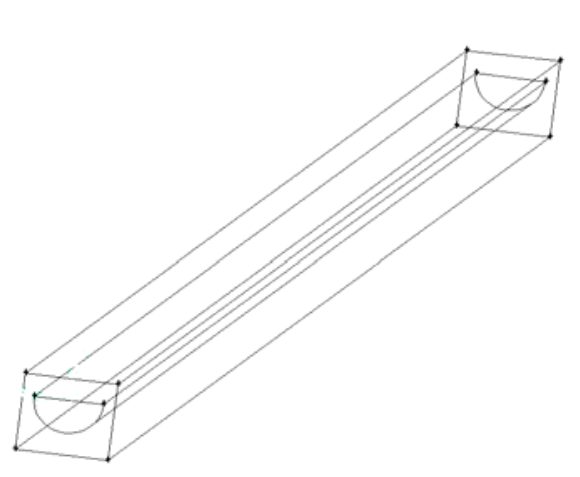

(a)

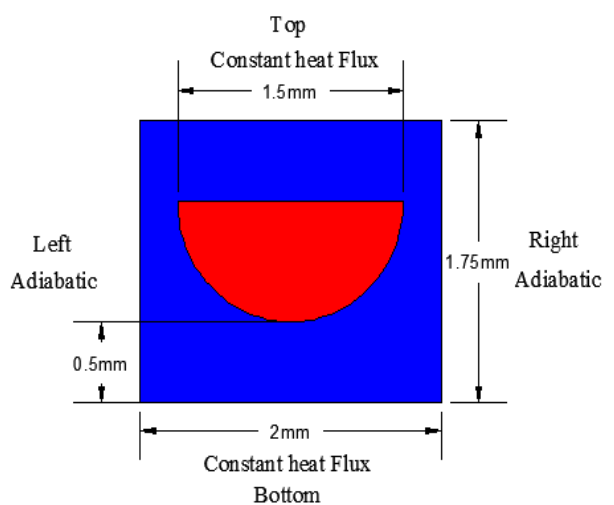

(b)

Figure 4. Schematic diagram of (a) Straight channel geometric model and (b) cross-section of straight channel.

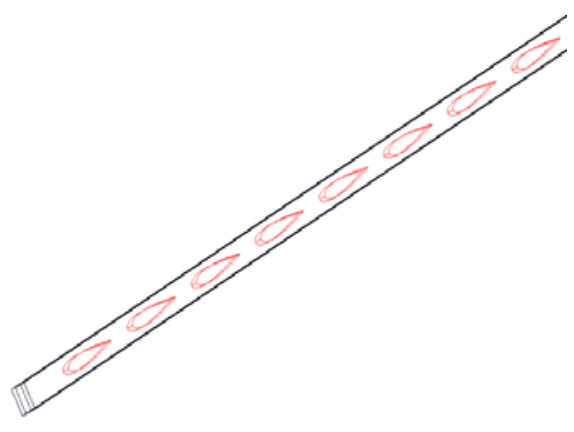

(a)

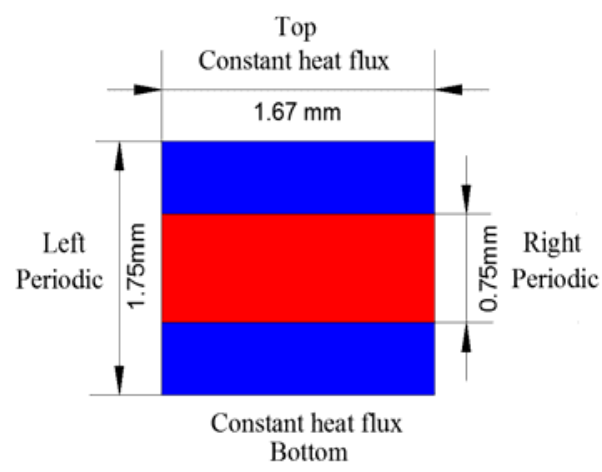

(b)

Figure 5. Schematic diagram of (a) the airfoil fin channel geometric model and (b) cross-section of airfoil fin channel.

Then, to study the effects of airfoil fin arrangements on the flow and heat transfer characteristics of supercritical LNG, six periodic fin structures along the flow direction and three along the transverse direction were selected as the simulation domain. The airfoil fin PCHE has three important geometric parameters (Figure 3). The separation distance of staggered arrangement is presented by $L_{s}$. There is a periodicity between an un-staggered arrangement and a fully staggered arrangement. $L_{h}$ indicates the separation distance between one airfoil head and adjacent airfoil head in a row. The separation distance between one row and adjacent row in the vertical direction is indicated by $L_{v}$. Herein, $L_{h}$ was $6 \mathrm{~mm}, L_{s}$ varied from 0 to $4 \mathrm{~mm}$ and $L_{v}$ changed from $1.3 \mathrm{~mm}$ to $3 \mathrm{~mm}$. According to the configuration, the width $(\mathrm{W})$ of the heat transfer region of the entire domain varied from $3.9 \mathrm{~mm}$ to $9 \mathrm{~mm}$. The vertical pitch $L_{v}=1.67 \mathrm{~mm}$ and staggered pitch $L_{s}=0 \mathrm{~mm}$ were selected as the baseline model.

A schematic diagram of the simulation domain (Figure 6) showed that $L_{v}=1.67 \mathrm{~mm}$ and $L_{s}=0 \mathrm{~mm}$. The working fluid was supercritical LNG, and the material of substrate plates and fins was steel. The mass flux inlet was applied for the inlet boundary condition of the simulation domain, and the inlet temperature and reference mass flux were set at $121 \mathrm{~K}$ and $325 \mathrm{~kg} / \mathrm{m}^{2} \cdot \mathrm{s}$, respectively. The outlet boundary condition was set as pressure outlet. As shown in Figure 7, a periodic boundary condition in the left/right positions, as well as a constant heat flux applied to the top and bottom positions is $58,713.75 \mathrm{~W} / \mathrm{m}^{2}$. 


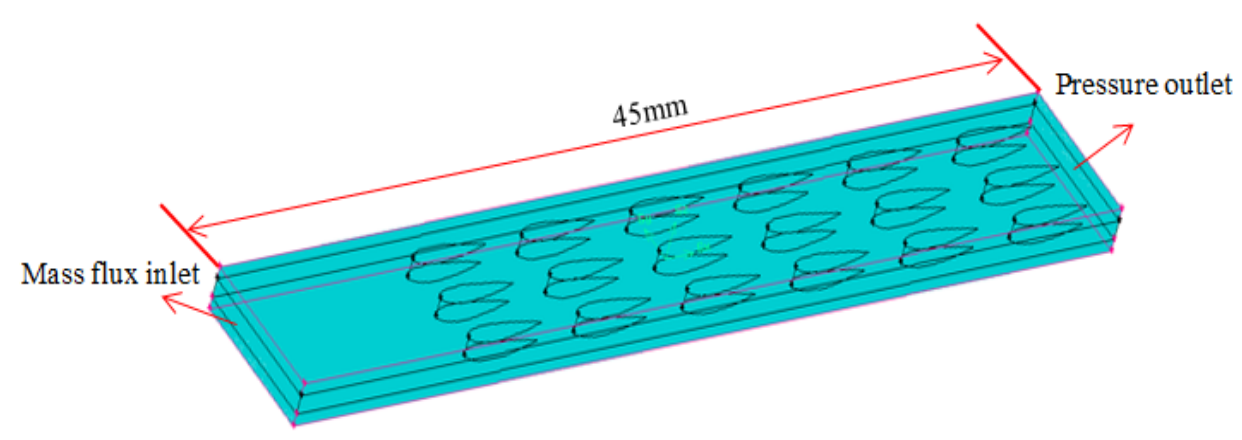

Figure 6. 3D view of computational domain for airfoil fin PCHE.

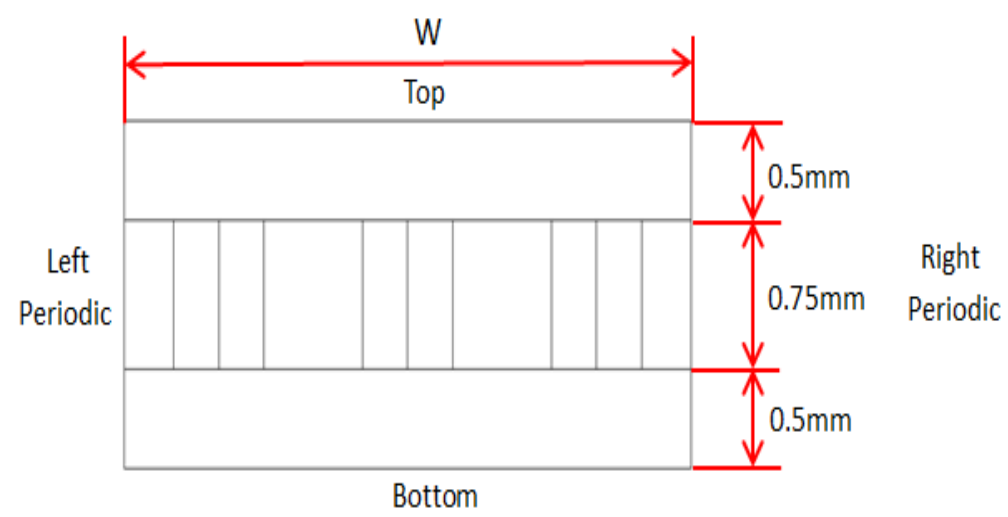

Figure 7. Schematic diagram of airfoil fin PCHE.

\subsection{Numerical Method and Grid Independence}

ANSYS Fluent 14.5 was used for our numerical evaluation of the airfoil fin PCHE. The set mass flow rate corresponded to turbulent flow regimes in the PCHE cold channels. It is important to select a proper turbulence model for numerical calculations. Kim and No [10] reported that the shear stress transport k- $\omega$ model (SST k- $\omega$ ) [11] predicted a fine grid near the wall in supercritical calculation extremely well. Therefore, the SST k- $\omega$ model was used in this study. A detailed description of the SST $\mathrm{k}-\omega$ model can be found in [37]. The semi-implicit method pressure linked equation algorithm was used to resolve the coupling of velocity and pressure. Before solution convergence, the residual for every variable was required to be less than $10^{-6}$. Meanwhile, the second order upwind, which has a smaller truncation error than that of the first order upwind, was used in the momentum equation and energy equation to ensure the accuracy of simulation.

The structured computation mesh was generated by GAMBIT. The number of meshes was different for all cases on account of various dimensions of the simulation domain, so the model with staggered number $L_{s}=0 \mathrm{~mm}$ and vertical number $L_{v}=1.67 \mathrm{~mm}$ was selected as the baseline model. The mesh dependence test dominated the density of meshes (Figure 8). The influence of grid density on the accuracy of calculated results was studied by comparing six sets of grid numbers: 1302567, 1762753, 2415689, 3269854, 3594425 and 4196856 cells. By comparing the outlet temperature and Nusselt number, the optimal grid of 3594422 was selected considering the accuracy and computational efficiency. As shown in Figure 9, the grids are encrypted near the wall surfaces of fins and substrate plates to ensure that $y^{+}$is lower than 1 . Six boundary layers were established near the top and bottom walls and fin surfaces because of the strict requirements for boundary grid in the supercritical flow and heat transfer, and the thickness of the first boundary layer was $0.01 \mathrm{~mm}$. 


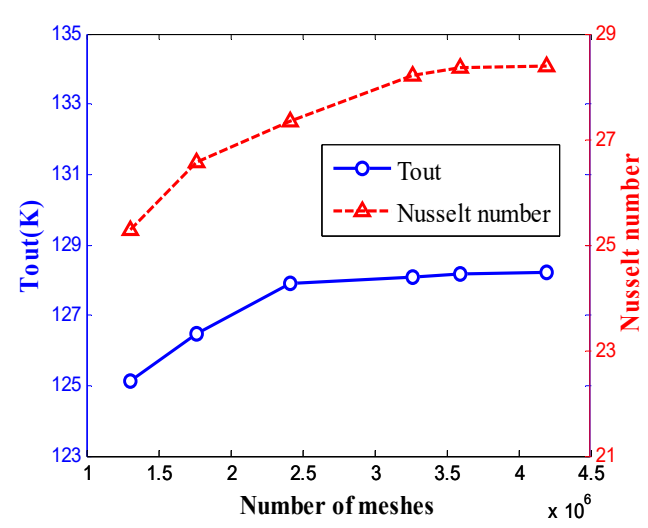

Figure 8. Dependency test of number of meshes.

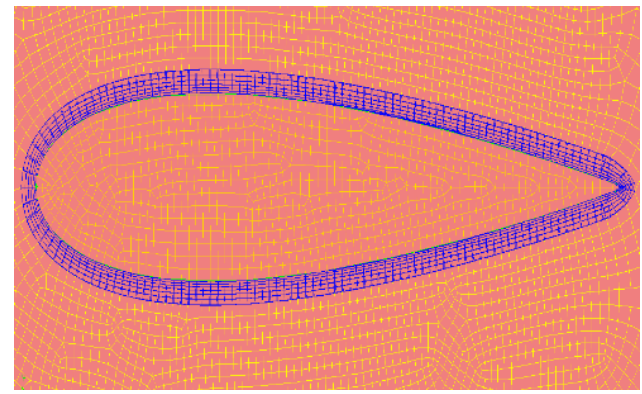

Figure 9. Top view of selected grid system.

\subsection{Model Validation}

In the present study, the heat transfer and flow characteristics of supercritical LNG in PCHE were investigated numerically. The results of CFD analysis should be compared with the experimental data for validating analysis methodology. However, due to the flammable and explosive properties of LNG when the gas leaks or ventilation is insufficient at high pressure, supercritical nitrogen was selected to substitute LNG as the cold fluid. A crossflow PCHE with airfoil fin channels on the cold side and straight channels on the hot side was manufactured using stainless steel 316L (Figure 10). The airfoil fin with the chord length of $4 \mathrm{~mm}$ and the maximum thickness of $0.8 \mathrm{~mm}$ was selected. A experimental system was established to study the thermal-hydraulic performance of airfoil fin PCHE using supercritical nitrogen as the cold fluid and R22 as the hot fluid (Figure 11). The inlet temperature of nitrogen was $102 \mathrm{~K}$ when its pressure was varied from $5.5 \mathrm{MPa}$ to $7.5 \mathrm{MPa}$. The mass flux of nitrogen varied from 233 to $421 \mathrm{~kg} / \mathrm{m}^{2} \cdot \mathrm{s}$, corresponding to turbulent flow regimes on the cold side of airfoil fin PCHE. In short, this PCHE had a good heat transfer ability at high pressure and low temperature. The overall heat transfer coefficient of this PCHE ranged from 850 to $2600 \mathrm{~W} / \mathrm{m}^{2} \mathrm{~K}$, and the heat transfer efficiency was up to approximately $98 \%$.

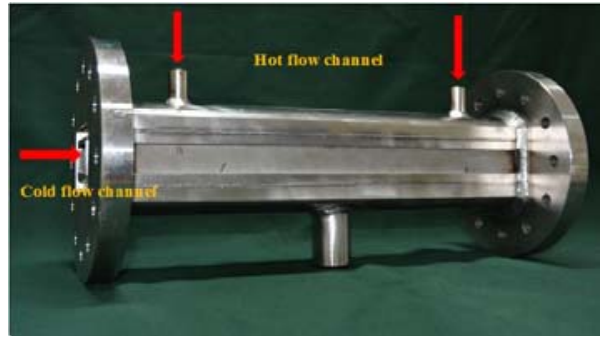

(a)

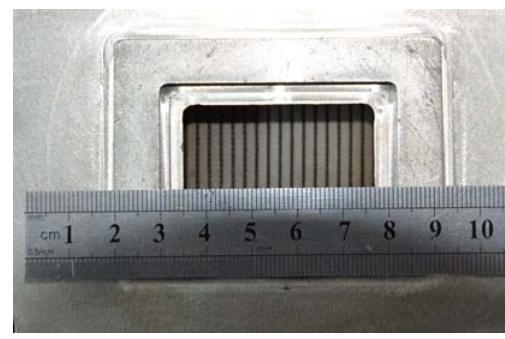

(b)

Figure 10. (a) Tested airfoil fin PCHE and (b) cold channel of airfoil fin PCHE. 


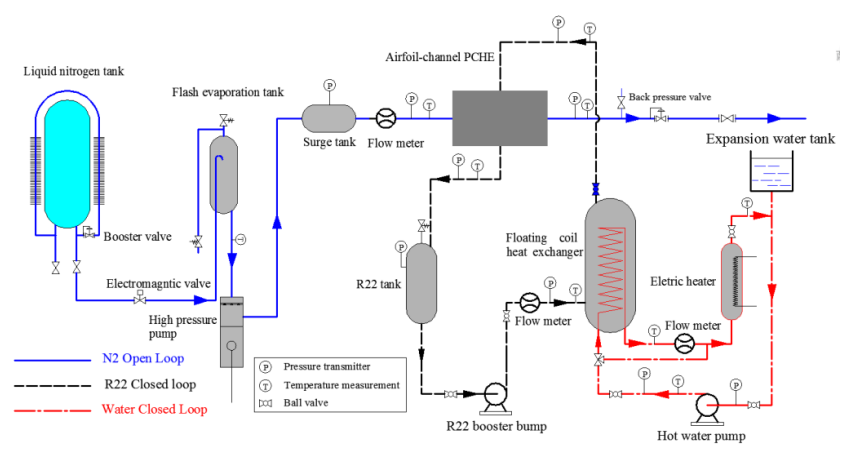

(a)

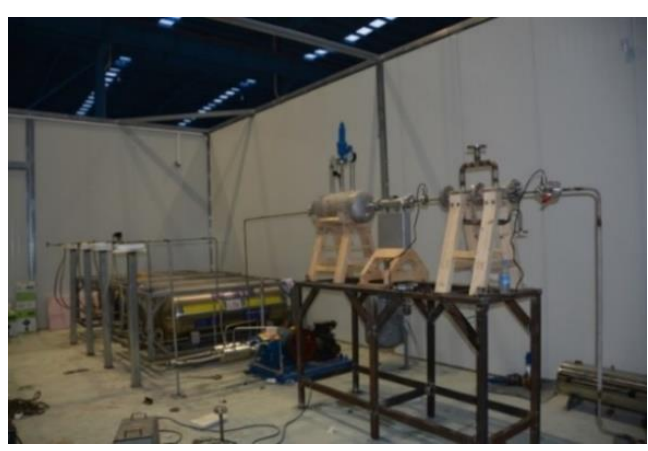

(b)

Figure 11. Experimental system with airfoil fin PCHE of (a) Schematic diagram of experimental set-up and (b) Photo of experimental system.

Figure 10 displays the schematic diagram for the internal core structure of airfoil fin PCHE. It is rather complex to simulate the heat transfer processes of the total tested airfoil fin PCHE, and this study focused on the heat transfer and flow performance of cold fluid. Therefore, a single airfoil fin channel of cold side with full length $(400 \mathrm{~mm})$ which used supercritical nitrogen as the working fluid was selected to simulate and to compare with the experimental data (Figure 3). The numerical model of this section was the same as that in Figure 5, except for the length. The inlet temperature of nitrogen was $102 \mathrm{~K}$ when its pressure was varied from $5.5 \mathrm{MPa}$ to $7.5 \mathrm{MPa}$. The mass flux of nitrogen was $421 \mathrm{~kg} / \mathrm{m}^{2} \cdot \mathrm{s}$, corresponding to turbulent flow regimes on the cold side of airfoil fin PCHE. The differences in the pressure drop and outlet temperature of the cold side between the numerical solutions and the experimental data were compared using Equation (1):

$$
\text { Error }=\frac{C F D-\text { Experiment }}{\text { Experiment }} \times 100 \%
$$

The pressure drop differences between the experimental and simulation results were analyzed when the mass flux was $421 \mathrm{~kg} / \mathrm{m}^{2} \cdot \mathrm{s}$ (Table 2). The numerical results differed from the experimental data by $6.9 \%$ on average and by $11.62 \%$ at maximum. The deviation may be attributed to the inlet and outlet header pressure drop, as well as the uncertainty of pressure transmitters. Besides, the difference between numerical and experimental outlet temperatures on the cold side had an average error of $0.735 \%$ and the maximum difference of $1.127 \%$. Therefore, the numerical data were in fairly good agreement with the experimental data, and the numerical model and method used herein were reliable.

Table 2. Comparisons of simulation and experiment results.

\begin{tabular}{ccccccc}
\hline Pressure (MPa) & $\begin{array}{c}\text { Experiment } \\
\text { Results of } \\
\mathbf{\Delta} / \mathbf{L} \mathbf{( P a} / \mathbf{m})\end{array}$ & $\begin{array}{c}\text { Simulation } \\
\text { Results of } \\
\mathbf{\Delta} / \mathbf{L} \mathbf{( P a} / \mathbf{m})\end{array}$ & Error $\mathbf{\%})$ & $\begin{array}{c}\text { Experiment } \\
\text { Results of } \\
\boldsymbol{T}_{\text {out }} \mathbf{( K )}\end{array}$ & $\begin{array}{c}\text { Simulation } \\
\text { Results of } \\
\boldsymbol{T}_{\text {out }} \mathbf{( K )}\end{array}$ & Error (\%) \\
\hline 5.5 & $37,090.61172$ & $35,226.12$ & $5.03 \%$ & 279.45 & 278.13 & $0.472 \%$ \\
6 & $33,988.7737$ & $32,023.7$ & $5.78 \%$ & 281.15 & 281.96 & $0.288 \%$ \\
6.5 & $25,650.67624$ & $27,635.15$ & $7.74 \%$ & 282.55 & 283.67 & $1.12 \%$ \\
7 & $24,175.74669$ & $26,985.37$ & $11.62 \%$ & 284.35 & 285.96 & $0.669 \%$ \\
7.5 & $23,834.30936$ & $24,865.35$ & $4.33 \%$ & 285.65 & 288.87 & $1.127 \%$ \\
\hline
\end{tabular}

However, Figure 1 shows that the physical properties of supercritical fluid change substantially with rising temperature during heat transfer. The local heat transfer and flow characteristics of supercritical fluid cannot be obtained in the experimental apparatus. Therefore, the local parameters of the airfoil fin PCHE were obtained through numerical simulation. 


\section{Objective Function Parameters}

As the characteristic length of the channel, hydraulic diameter $D_{h}$ is an important value in dimensionless analysis. It is defined as four times the cross-sectional area over a perimeter in the straight channel. Owing to the continual changes of cross-sectional area and perimeter, the hydraulic diameter cannot be the same as that of straight channel, as shown in Figure 12. Nevertheless, the airfoil fin placement in Figure 3 is periodic. Therefore, the hydraulic diameter can be defined by the equations below [37].

$$
\begin{gathered}
V=\left(L W-S_{a}\right) t \\
S=2\left(\frac{P_{a} t}{2}\right)+2\left(L-L_{c}\right) t+2\left(W L-S_{a}\right) \\
D_{h}=4 V / S
\end{gathered}
$$

where $S_{a}$ is the top area of airfoil fin, and $P_{a}$ is the perimeter of airfoil fin. $V$ and $S$ indicate the volume and side surface area of flow channel, respectively.

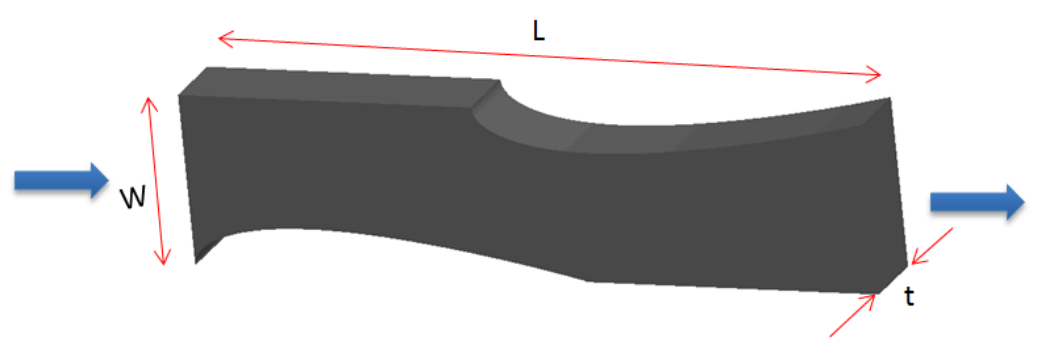

Figure 12. Schematic diagram for the calculation of hydraulic diameter.

The convective heat transfer coefficient can be obtained by the following equation:

$$
h=\frac{q_{w}}{T_{\text {wall }}-T_{b}}=\frac{q_{w}}{T_{\text {wall }}-\left(T_{\text {out }}+T_{\text {in }}\right) / 2}
$$

where $q_{w}$ is the area-averaged wall heat flux, $T_{\text {wall }}$ is the area-average wall temperature, and $T_{\text {in }}, T_{\text {out }}$ and $T_{b}$ are the inlet, outlet and bulk temperatures of LNG obtained from the Fluent data respectively.

The Nusselt number is defined below:

$$
N u=\frac{h D_{h}}{\lambda}
$$

where $D_{h}$ is the channel hydraulic diameter, and $\lambda$ is the thermal conductivity of LNG.

The Reynolds number can be calculated by Equation (7):

$$
R e=\frac{v \rho D_{h}}{\mu}
$$

where $D_{h}$ is the channel hydraulic diameter, $\rho$ is the density of LNG and $\mu$ is the dynamic viscosity of LNG.

The friction and acceleration effects caused by the density difference between inlet and outlet can result in the pressure drop:

$$
\begin{gathered}
\Delta P=\Delta P_{a c c}+\Delta P_{\text {fric }} \\
\Delta P_{a c c}=G^{2}\left(\frac{1}{\rho_{\text {out }}}-\frac{1}{\rho_{\text {in }}}\right) \\
\Delta P_{\text {fric }}=\frac{2 f L_{u} \rho v^{2}}{D_{h}}
\end{gathered}
$$


where $\Delta P$ is the total pressure drop, $\Delta P_{\text {acc }}$ is the acceleration pressure drop and $\Delta P_{\text {fric }}$ is the friction pressure drop.

The Fanning friction factor $f$ is defined as below:

$$
f=\frac{\tau_{w}}{\frac{1}{2} \rho u_{m}^{2}}
$$

where $\tau_{w}$ is the wall shear stress.

In terms of pressure drop, the Euler number was selected as a representative pressure loss coefficient in this study. It reflects the relationship between pressure drop and dynamic velocity head, as well as the relative momentum loss rate:

$$
E u=\frac{\Delta P}{\rho u^{2} / 2}
$$

\section{Results and Discussion}

\subsection{Comparison of Straight Channel PCHE and Airfoil Fin PCHE}

In the present study, the heat transfer and flow characteristics of supercritical LNG in a straight channel PCHE and an airfoil fin PCHE with the same hydraulic diameter $\left(D_{h}=0.917 \mathrm{~mm}\right)$ were numerically investigated. Figure 13 shows the velocity contours of supercritical LNG in airfoil fin and straight channel PCHEs when the mass flux is $325 \mathrm{~kg} / \mathrm{m}^{2} \cdot \mathrm{s}$. When supercritical LNG was gradually heated, the bulk velocity significantly increased because of reduced density. However, the velocity increased rapidly in airfoil fin channel owing to continuous expansion and contraction in the sectional area of flow channel. The maximum velocity in the narrowest flow channel was nearly 3 times that in the inlet. Therefore, airfoil fins evidently disturbed supercritical LNG, which increased heat transfer and flow resistance simultaneously.

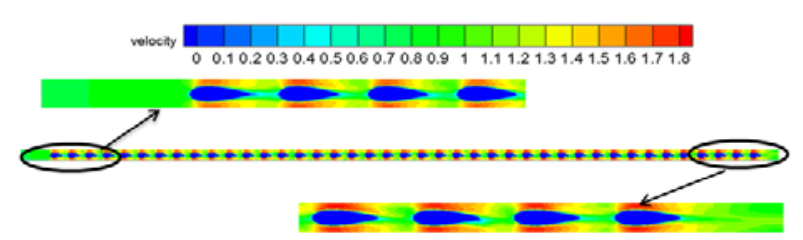

(a)

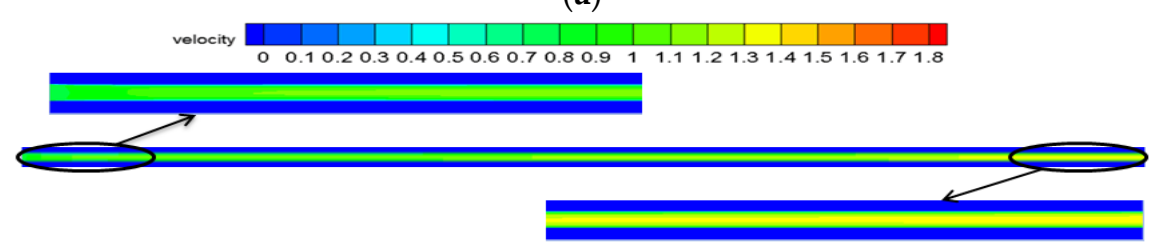

(b)

Figure 13. (a) Plots of velocity contours in airfoil fin channel and (b) straight channel when mass flux is $325 \mathrm{~kg} / \mathrm{m}^{2} \cdot \mathrm{s}$.

To evaluate the effect of mass flux, six different mass fluxes were tested for straight channel and airfoil fin PCHEs. Figure 14 display the changes of heat transfer coefficient and Nusselt number at various mass fluxes respectively. Since the turbulence intensity of flow significantly increased with rising mass flux, the heat transfer coefficient and Nusselt number rapidly increased in both PCHEs. Also, the Nusselt number of airfoil fin PCHE exceeded that of straight channel PCHE. As we all know, the heat transfer and flow of a heat exchanger were affected by fins predominantly in two ways: giving rise to disturbance and enlarging heat transfer area. Therefore, the airfoil fin PCHE showed better thermal performance than that of the straight channel PCHE at the same mass flux and hydraulic 
diameter. For example, when mass flux $G=425 \mathrm{~kg} / \mathrm{m}^{2} \cdot \mathrm{s}$ and $G=725 \mathrm{~kg} / \mathrm{m}^{2} \cdot \mathrm{s}, N u$ values of airfoil fin PCHE were 1.48 and 1.36 times those of the straight channel PCHE, respectively.

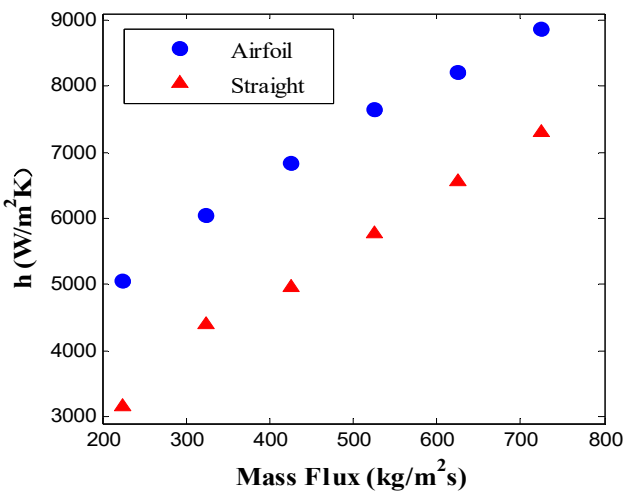

(a)

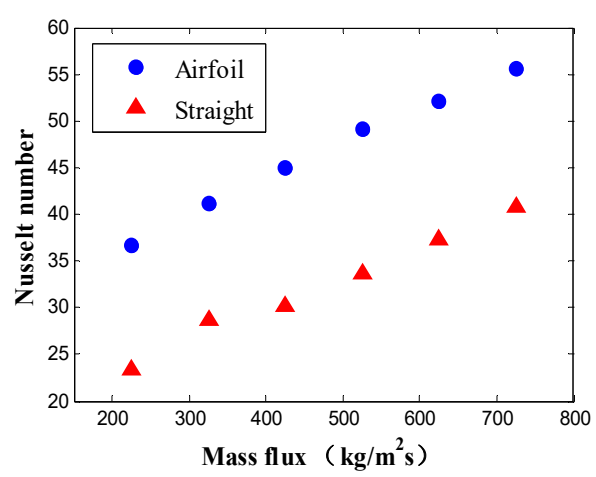

(b)

Figure 14. (a) Heat transfer coefficient $h$ and (b) Nusselt number as a function of mass flux.

The effects of mass flux on the Euler number and Fanning friction factor of the straight channel PCHE and the airfoil fin PCHE were also assessed (Figure 15). The Euler number of the straight channel PCHE surpassed that of the airfoil fin PCHE. For example, when mass flux $G=425 \mathrm{~kg} / \mathrm{m}^{2} \cdot \mathrm{s}$, the Euler number of the airfoil fin PCHE was $89.7 \%$ of that of the straight channel PCHE. Generally, pressure drop increases with rising mass flux. However, Figure 16 shows that the Euler number calculated by Equation (12) decreases as the mass flux increases. According to this equation, the Euler number is proportional to pressure drop $\Delta P$ but inversely proportional to $v^{2}$. Obviously, the velocity of supercritical LNG rose with increasing mass flux, although it also raised the pressure drop. Nevertheless, $v^{2}$ exerted a stronger effect on $E u$ than on pressure drop, so the increase of mass flux led to decrease of the Euler number.

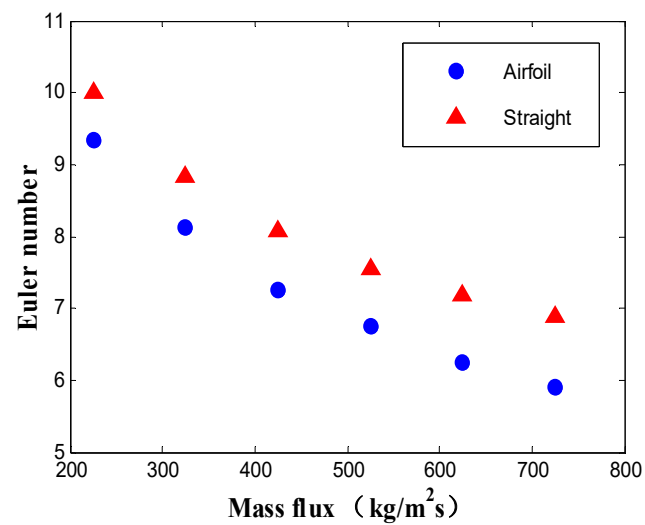

(a)

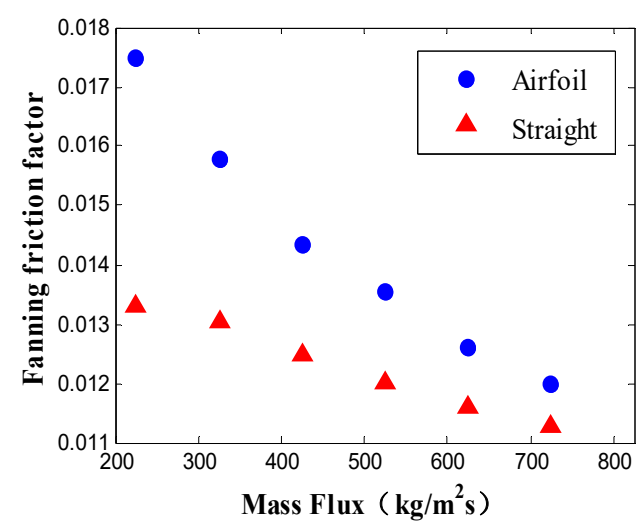

(b)

Figure 15. (a) Euler number and (b) Fanning friction factor as a function of mass flux.

The heat transfer quantity and pressure drop, as the main indices of heat exchanger performance, were described as the Nusselt number and the Euler number herein, both helping to optimize the arrangement of the airfoil fins. Generally, a specific objective function is used to verify an optimal design. The ratio of Nusselt number to Euler number, i.e., $N u / E u$, was employed as the objective function to evaluate the performance of the heat exchanger. Figure 16 describes $N u / E u$ as a function of mass flux. The minimum and maximum differences of $N u / E u$ between the straight channel PCHE and the airfoil fin PCHE were $46.2 \%$ and $51.07 \%$, respectively. Evidently, the airfoil fin PCHE had a better thermal-hydraulic performance, and the difference of $N u / E u$ between the airfoil fin and straight 
channel PCHEs increased with rising mass flux. Hence, fin arrangement is recommended for the airfoil fin PCHE.

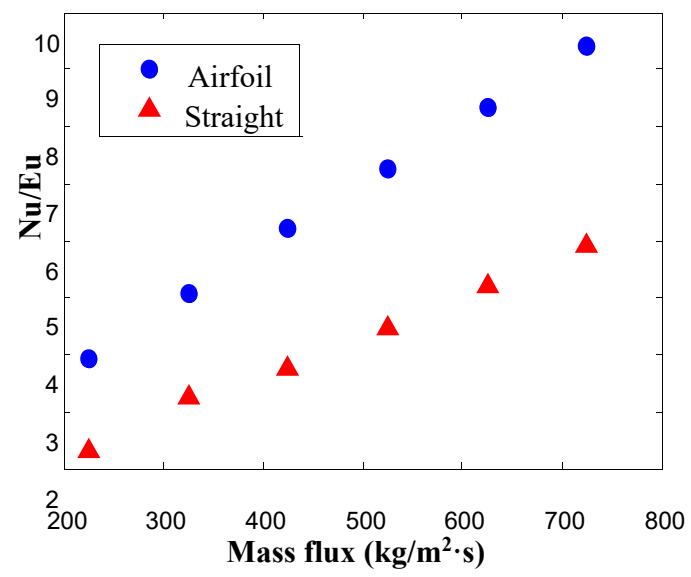

Figure 16. $N u / E u$ as a function of mass flux.

\subsection{Effect of Fin Arrangement: Staggered Pitch $\left(L_{s}\right)$}

Fins affect flow and heat transfer primarily through their shapes and arrangements in a PCHE. In this section, airfoil fins were arranged in parallel $\left(L_{S}=0 \mathrm{~mm}\right)$ and staggered $\left(L_{S}=1 \sim 4 \mathrm{~mm}\right)$ in the transverse direction of the PCHE.

In an airfoil fin PCHE, the airfoil fins with wide head and narrow tail favor the formation of a much smoother flow channel when arranged in a staggered manner, and the vortex separation could also be prevented by the streamlined fins, which may result in a smaller flow resistance in staggered arrangement than that in parallel arrangement. Figure 17 depicts the velocity contour of supercritical LNG in airfoil fin PCHE arranged in parallel and staggered manners when the vertical pitch $L_{v}=1.67 \mathrm{~mm}$. In the start of heating, the velocities of fluid were quite uniform and small in both staggered and parallel arrangements. However, owing to continuous expansion and contraction in the sectional area of flow channel, the non-uniformity of velocity became obvious in parallel arrangement as the velocity increased in the flow direction. Therefore, a staggered arrangement of airfoil fins benefited the formation of smooth flow channel and the improvement of flow field uniformity.

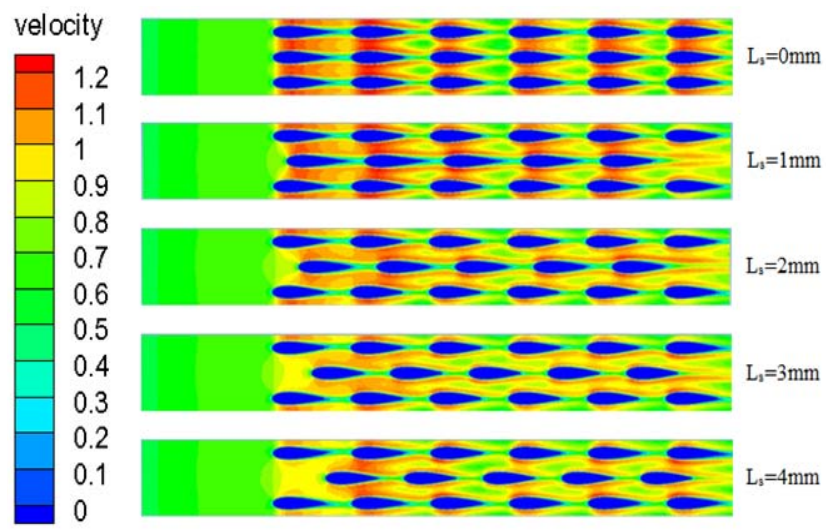

Figure 17. Velocity contour in PCHE with airfoil fins arranged at $L_{v}=1.67 \mathrm{~mm}$.

Figure 18a shows the Nusselt numbers of an airfoil fin PCHE in parallel and staggered arrangements. Clearly, the airfoil fins with staggered arrangement showed better thermal performance than that of the airfoil fins with parallel arrangement. However, at the same vertical pitch $L_{v}$, 
the Nusselt numbers of parallel and staggered arrangements were similar. The Nusselt number at $L_{s}=0 \mathrm{~mm}$ differed from that at $L_{s}=4 \mathrm{~mm}$ by $6.9 \%$ when the vertical number $L_{v}=3 \mathrm{~mm}$.

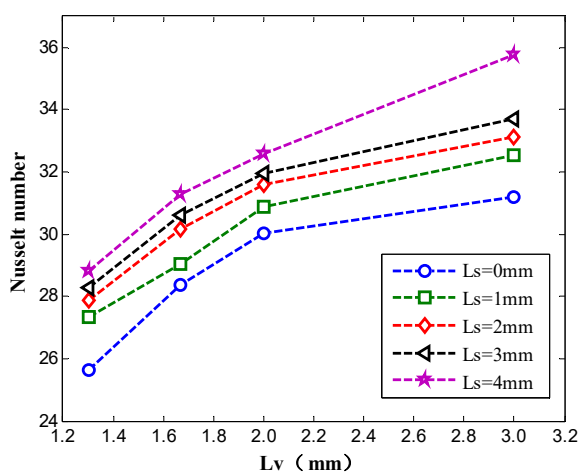

(a)

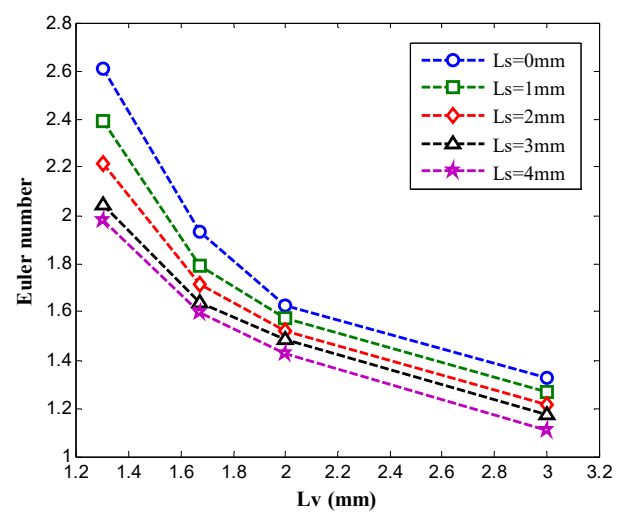

(c)

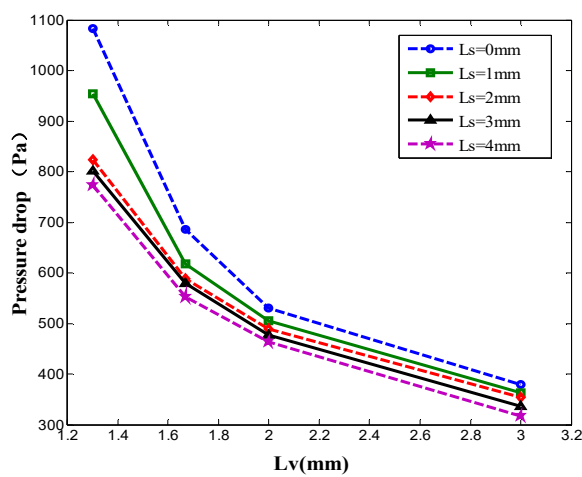

(b)

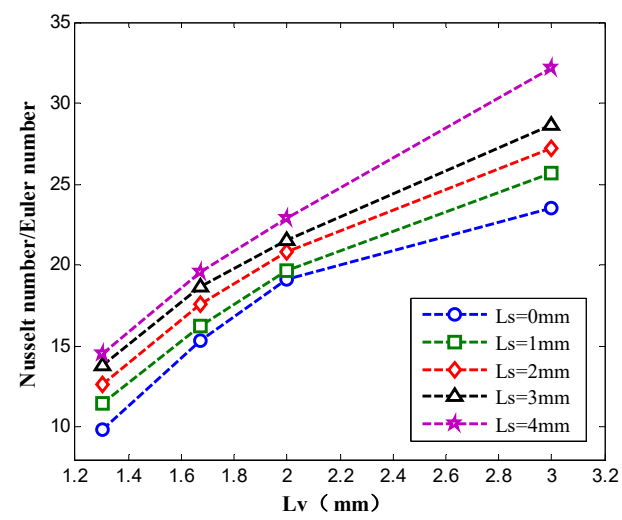

(d)

Figure 18. Effect of $L_{v}$ on (a) Nusselt number, (b) pressure drop, (c) Euler number and (d) Nu/Eu.

In addition, the flow resistance increased as the staggered pitch $L_{S}$ decreased. Figure $18 b$,c present the pressure drop and Euler number with the staggered pitch $\left(L_{s}\right)$ at different $L_{v}$ in an airfoil fin PCHE. In Figure 18c, the Euler number in staggered arrangement $\left(L_{s}=1 \mathrm{~mm}\right.$ ) is smaller (a maximum decrease of $9.86 \%)$ than that in parallel arrangement $\left(L_{S}=0 \mathrm{~mm}\right)$, with the difference enlarging as the staggered pitch $\left(L_{S}\right)$ increases at the same vertical pitch $L_{v}$.

Figure 18d presents the dependence of $\mathrm{Nu} / E u$ on $L_{s} . \mathrm{Nu} / E u$ increased with rising staggered number $L_{s} . \quad L_{s}=0 \mathrm{~mm}$ had a lower $\mathrm{Nu} / E u$ (about 27\%) than that at $L_{s}=4 \mathrm{~mm}$, suggesting that $L_{s}=4 \mathrm{~mm}$ had better heat transfer and pressure drop. Probably, pressure drop was more susceptible to $L_{S}$ than heat transfer. Collectively, staggered arrangement was superior to parallel arrangement in airfoil fin PCHE, manifested as reduced flow resistance and improved total thermal-hydraulic performance.

\subsection{Effect of Fin Arrangement: Vertical Pitch $\left(L_{\vartheta}\right)$}

When $L_{h}(6 \mathrm{~mm})$ is kept constant, $L_{v}$ directly determines the density of fins and the width of flow channel. Therefore, the effect of vertical separation distance $\left(L_{v}\right)$ on the thermal-hydraulic performance of an airfoil fin PCHE was assessed.

The velocity contours of supercritical LNG in airfoil fin PCHE arranged at different $L_{v}$ when the staggered pitch $L_{s}=1.67 \mathrm{~mm}$ are presented in Figure 19. A smaller vertical pitch $L_{v}$ resulted in a higher velocity, thereby augmenting the flow resistance. In fact, a smaller $L_{v}$ led to a narrower sectional area of flow channel, so that the flow velocity increased with decreasing $L_{v}$ at the same mass flux. The maximum velocities of LNG in the narrowest sectional of flow channel were $1.35 \mathrm{~m} / \mathrm{s}$ and 
$1.79 \mathrm{~m} / \mathrm{s}$ in the airfoil fins with $L_{s}=3 \mathrm{~mm}$ and $L_{s}=1.3 \mathrm{~mm}$, respectively. Therefore, the turbulence intensity of fluid and the flow resistance were both enhanced locally.

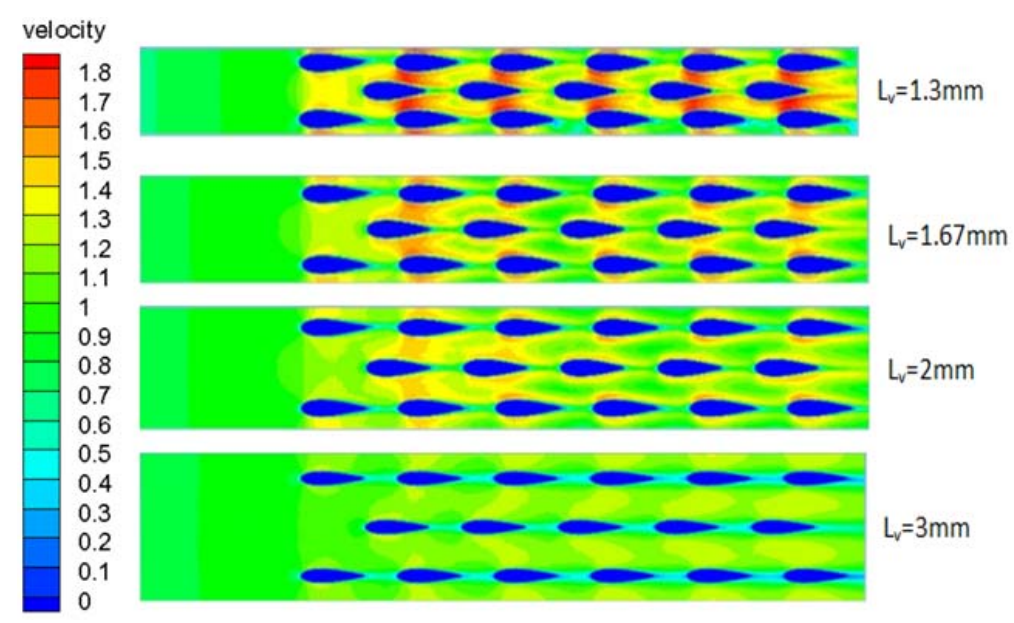

Figure 19. Velocity contour in PCHE with airfoil fins arranged at $L_{S}=4 \mathrm{~mm}$.

Figure 20 shows the variations of heat transfer coefficient $h$ and Nusselt number $(\mathrm{Nu})$ with increasing fin distance $\left(L_{v}\right)$ at different $L_{s}$ in an airfoil fin PCHE. The convective heat transfer coefficient $h$ decreased with rising $L_{v}$ at the same $L_{s}$, which may attributed to the decreased flow velocity. However, $h$ and $N u$ changed oppositely with increasing $L_{v}$, mainly because the hydraulic diameter increased significantly faster than $h$ decreased with rising $L_{v}$. For example, the hydraulic diameter at $L_{v}=3 \mathrm{~mm}$ was nearly 2.7 times that at $L_{v}=1.3 \mathrm{~mm}$, and $h$ at $L_{v}=1.3 \mathrm{~mm}$ was 1.2 times that at $L_{v}=1.3 \mathrm{~mm}$ when $L_{S}=4 \mathrm{~mm}$. Thus, the Nusselt number increased with rising $L_{v}$ of airfoil fins.

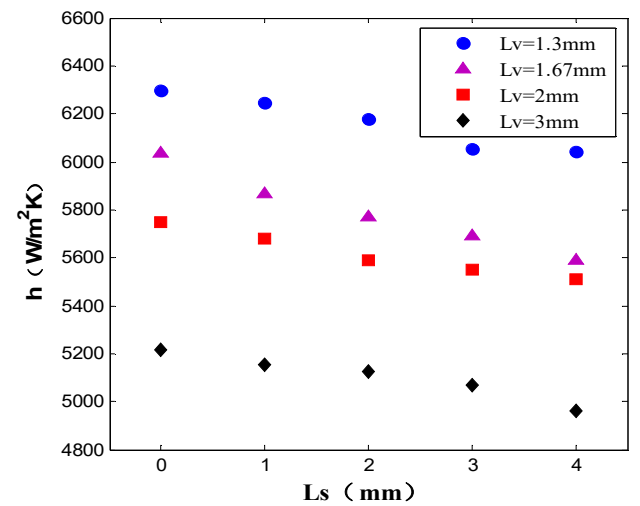

(a)

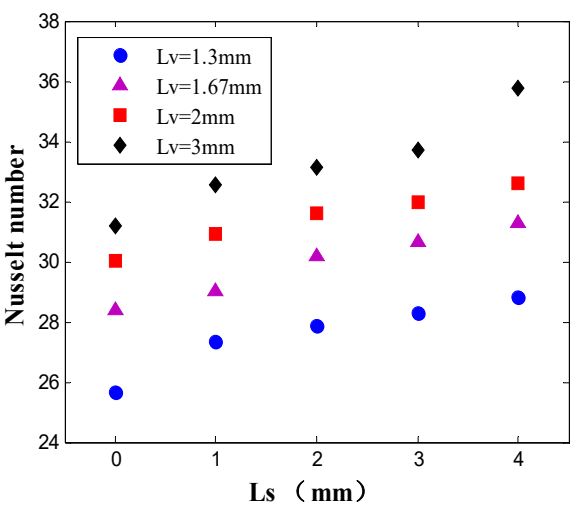

(b)

Figure 20. Effect of $L_{S}$ on (a) heat transfer coefficient $h$ and (b) Nusselt number.

Figure 21a shows the dependence of the Euler number on $L_{v}$. The total pressure drop decreased as $L_{v}$ increased, so the Euler number dropped more apparently with increasing $L_{v}$ at the same $L_{s}$. The Euler number at $L_{v}=3 \mathrm{~mm}$ was only $56 \%$ of that at $L_{v}=1.3 \mathrm{~mm}$. Obviously, at the same $L_{s}$, reducing $L_{v}$ slightly facilitated heat transfer, though it also considerably elevated pressure drop. 


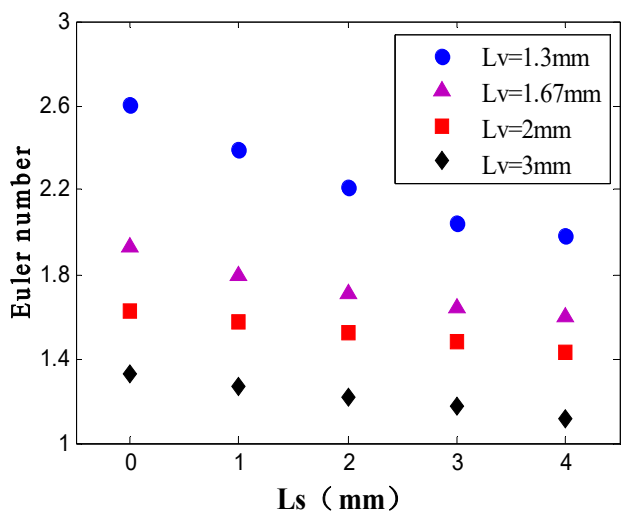

(a)

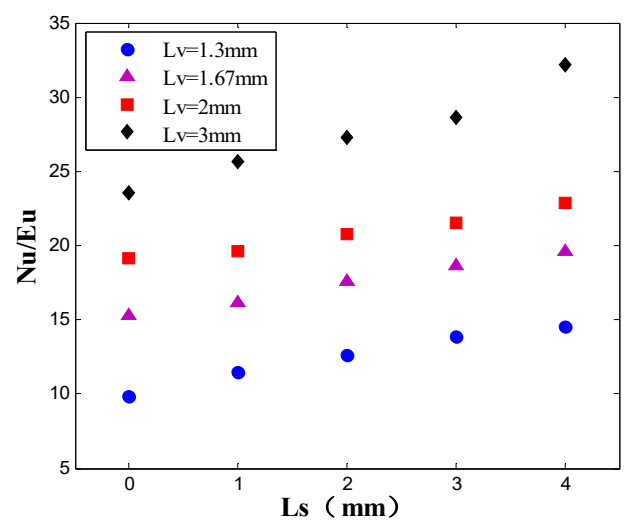

(b)

Figure 21. Effect of $L_{s}$ on (a) Euler number and (b) $N u / E u$.

As described in Section 4.1, a specific objective function $N u / E u$ was used to indicate the performance of the airfoil fin PCHE. As illustrated in Figure 21b, Nu/Eu noticeably rises as $L_{v}$ increases. $\mathrm{Nu} / \mathrm{E} u$ at $L_{v}=3 \mathrm{~mm}$ is nearly 3 times and 1.7 times those at $L_{v}=1.3 \mathrm{~mm}$ and $L_{v}=2 \mathrm{~mm}$ respectively, indicating that a dense fin arrangement was conducive to increasing the heat transfer rate. Meanwhile, it was inevitably more difficult to overcome flow resistance. Accordingly, fins should be sparsely arranged in an airfoil fin PCHE.

\section{Conclusions}

We here in aimed to clarify the thermal-hydraulic characteristics and optimal structure of a PCHE in which supercritical LNG was used as the working fluid. The effects of channel shape and fin arrangements on the flow resistance and heat transfer in the airfoil fin PCHE were numerically investigated as follows:

(1) The numerical model and methods were validated with experimental data. Supercritical liquid nitrogen was used as a cold fluid for simulation and experiment. The SST model followed by the enhanced wall treatment method well predicted the outlet temperature and pressure drop of a single airfoil fin in the PCHE. The error between the numerical and experimental data was within $14 \%$, indicating the heat transfer and flow characteristics of supercritical LNG in airfoil fin PCHE could be reliably simulated by the model and method.

(2) As a new type of discontinuous fins, airfoil fins can boost the thermal-hydraulic performance compared with that of a straight channel PCHE using supercritical LNG as the working fluid. The minimum and maximum differences of $N u / E u$ between straight channel and airfoil fin PCHEs were $46.2 \%$ and $51.07 \%$, respectively. The convective heat transfer coefficient and pressure drop increased in both PCHEs with rising mass flux.

(3) A staggered fin arrangement was more beneficial to the thermal-hydraulic performance of the airfoil fin PCHE than a parallel fin arrangement using supercritical LNG as the working fluid. At the same $L_{v}$ and $L_{h}$, airfoil fins arranged at $L_{s}=4 \mathrm{~mm}$ displayed better thermal-hydraulic performance than those of the fins at other $L_{s}$.

(4) The velocity of supercritical LNG in the airfoil fin channels increased along the channel length and then plummeted with increasing $L_{v}$. The effect of vertical number $L_{v}$ on the thermal-hydraulic performance of airfoil fin PCHE was more evident than that of staggered pitch $L_{s}$. Based on a comprehensive analysis of heat transfer coefficient and pressure drop, a sparser staggered arrangement of fins can enhance the thermal-hydraulic performance of an airfoil fin PCHE. 
Acknowledgments: The authors gratefully acknowledge that this work was Jiangsu marine and fishery science and technology innovation and extension project (HY2017-8) and Zhenjiang funds for the key research and development project (GY2016002-1).

Author Contributions: All authors contributed to the paper. Zhongchao Zhao was the director of the research project, put forward the study ideas and wrote this paper; The numerical simulation and data analysis was completed by Kai Zhao and Dandan jia; Pengpeng Jiang and Rendong Shen discussed experimental ideas and completed a part of the data analysis; the laboratory tests were completed by all authors.

Conflicts of Interest: The authors declare no conflict of interest.

\section{Nomenclature}

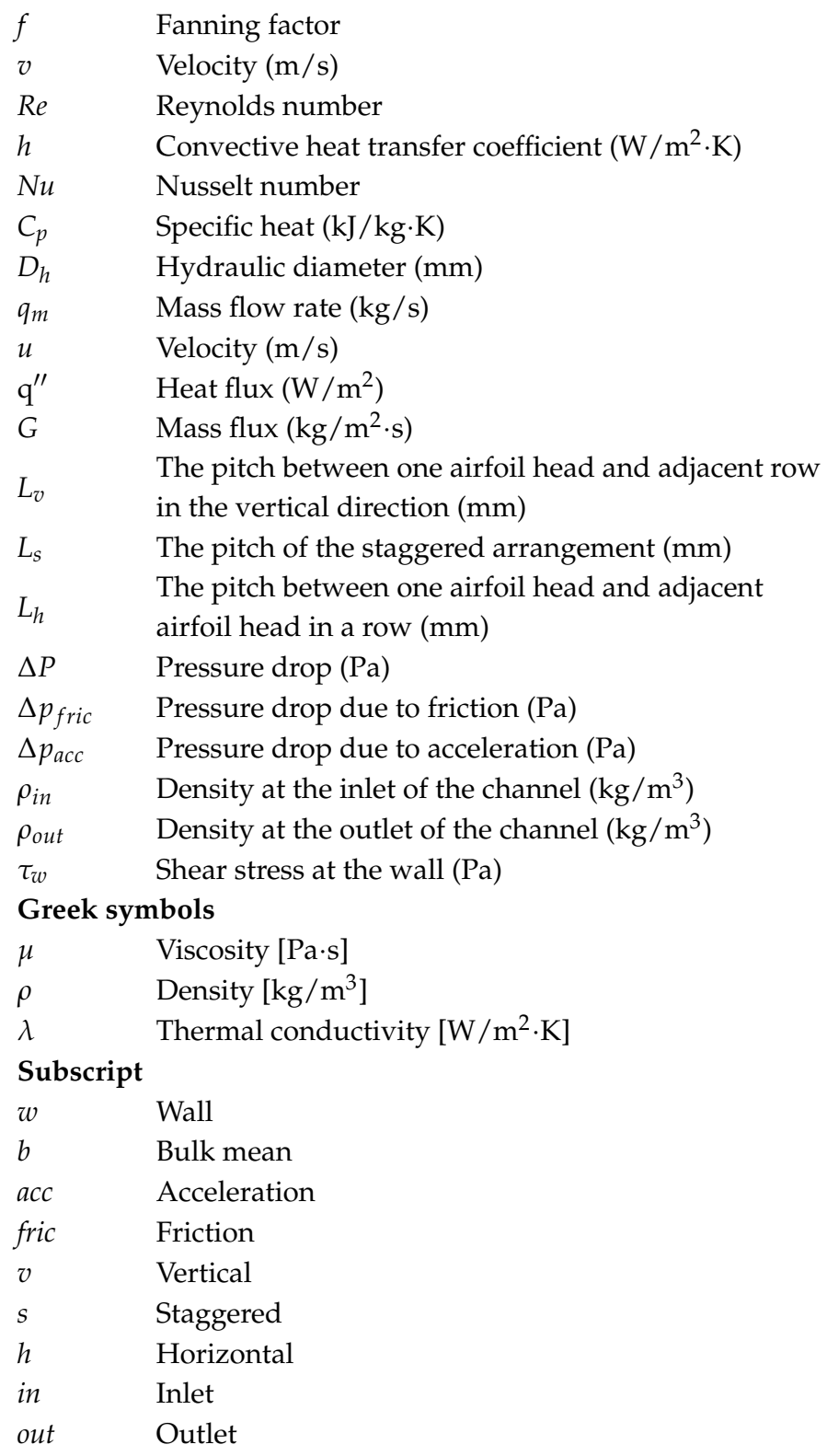

\section{References}

1. Yousefi, A.; Birouk, M. Investigation of natural gas energy fraction and injection timing on the performance and emissions of a dual-fuel engine with pre-combustion chamber under low engine load. Appl. Energy 2017, 189, 492-505. [CrossRef] 
2. Pham, T.N.; Long, V.N.D.; Lee, S.; Lee, M. Enhancement of single mixed refrigerant natural gas liquefaction process through process knowledge inspired optimization and modification. Appl. Therm. Eng. 2017, 110, 1230-1239. [CrossRef]

3. Pu, L.; Qu, Z.; Bai, Y.; Qi, D.; Song, K.; Yi, P. Thermal performance analysis of intermediate fluid vaporizer for liquefied natural gas. Appl. Therm. Eng. 2014, 65, 564-574. [CrossRef]

4. Wang, T.; Lin, B. China's natural gas consumption peak and factors analysis: A regional perspective. J. Clean. Prod. 2017, 142, 548-564. [CrossRef]

5. Pan, J.; Li, R.; Lv, T.; Wu, G.; Deng, Z. Thermal performance calculation and analysis of heat transfer tube in super open rack vaporizer. Appl. Therm. Eng. 2016, 93, 27-35. [CrossRef]

6. Liu, S.; Jiao, W.; Wang, H. Three-dimensional numerical analysis of the coupled heat transfer performance of LNG ambient air vaporizer. Renew. Energy 2016, 87, 1105-1112. [CrossRef]

7. Han, C.-L.; Ren, J.J.; Wang, Y.Q.; Dong, W.-P.; Bi, M.S. Experimental investigation on fluid flow and heat transfer characteristics of a submerged combustion vaporizer. Appl. Therm. Eng. 2017, 113, 529-536. [CrossRef]

8. Yoon, S.-J.; Sabharwall, P.; Kim, E.-S. Numerical study on crossflow printed circuit heat exchanger for advanced small modular reactors. Int. J. Heat Mass Transf. 2014, 70, 250-263. [CrossRef]

9. Tsuzuki, N.; Kato, Y.; Ishiduka, T. High Performance Printed Circuit Heat Exchanger. Appl. Therm. Eng. 2007, 27, 1702-1707. [CrossRef]

10. Kim, I.H.; No, H.C. Thermal hydraulic performance analysis of a printed circuit heat exchanger using a helium-water test loop and numerical simulations. Appl. Therm. Eng. 2011, 31, 4064-4073. [CrossRef]

11. Kim, I.H.; No, H.C.; Lee, J.I.; Jeon, B.G. Thermal hydraulic performance analysis of the printed circuit heat exchanger using a helium test facility and CFD simulations. Nucl. Eng. Des. 2009, 239, 2399-2408. [CrossRef]

12. Kim, I.H.; No, H.C. Physical model development and optimal design of PCHE for intermediate heat exchangers in HTGRs. Nucl. Eng. Des. 2012, 243, 243-250. [CrossRef]

13. Mylavarapu, S.K.; Sun, X.D.; Christensen, R.N.; Unocic, R.R.; Glosup, R.E.; Patterson, M.W. Fabrication and design aspects of high-temperature compact diffusion bonded heat exchangers. Nucl. Eng. Des. 2012, 249, 49-56. [CrossRef]

14. Mortean, M.V.V.; Paiva, K.V.; Mantelli, M.B.H. Diffusion bonded cross-flow compact heat exchangers: Theoretical predictions and experiments. Int. J. Therm. Sci. 2016, 110, 285-298. [CrossRef]

15. Hun, K.I.; Xiaoqin, Z.; Christensen, R.; Sun, X. Disign study and cost assessment of straighe, zigzag, S-shape, and OSF PCHEs for a FLiNaK-SCO 2 Secondary Heat Exchanger in FHRs. Ann. Nucl. Energy 2016, 94, 129-137.

16. Natesan, K.; Moisseytsev, A.; Majumdar, S. Preliminary issues associated with the next generation nuclear plant intermediate heat exchanger design. J. Nucl. Mater. 2009, 392, 307-315. [CrossRef]

17. Hosseini, S.B.; Khoshkhoo, R.H.; Malabad, S.M.J. Experimental and numerical investigation on particle deposition in a compact heat exchanger. Appl. Therm. Eng. 2017, 115, 406-417. [CrossRef]

18. Starace, G.; Fiorentino, M.; Longo, M.P.; Carluccio, E. A hybrid method for the cross flow compact heat exchangers design. Appl. Therm. Eng. 2017, 111, 1129-1142. [CrossRef]

19. Park, M.Y.; Song, M.S.; Kim, E.S. Development of tritium permeation model for Printed Circuit Heat Exchanger. Ann. Nucl. Energy 2016, 98, 166-177. [CrossRef]

20. Baek, S.; Kim, J.; Jeong, S.; Jung, J. Development of highly effective cryogenic printed circuit heat exchanger (PCHE) with low axial conduction. Cryogenics 2012, 52, 366-374. [CrossRef]

21. Kim, I.H.; No, H.C. Thermal-hydraulic physical models for a printed circuit heat exchanger covering he, he- $\mathrm{CO}_{2}$ mixture, and water fluids using experimental data and cfd. Exp. Therm. Fluid Sci. 2013, 48, $213-221$. [CrossRef]

22. Lee, S.-M.; Kim, W.Y. Comparative study on performance of a zigzag printed circuit heat exchanger with various channel shapes and configurations. Int. J. Heat Mass Transf. 2013, 49, 1021-1028. [CrossRef]

23. Lee, S.-M.; Kim, W.Y. Multi-objective optimization of arc-shaped ribs in the channels of a printed circuit heat exchanger. Int. J. Therm. Sci. 2015, 94, 1-8. [CrossRef]

24. Mylavarapu, S.K.; Sun, X.D.; Glosup, R.E.; Christensen, R.N.; Patterson, M.W. Thermal hydraulic performance testing of printed circuit heat exchangers in a high-temperature helium test facility. Appl. Therm. Eng. 2014, 65, 605-614. [CrossRef] 
25. Ma, T.; Li, L.; Xu, X.Y.; Chen, Y.T.; Wang, Q.W. Study on local thermal-hydraulic performance and optimization of zigzag-type printed circuit heat exchanger at high temperature. Energy Convers. Manag. 2015, 104, 55-66. [CrossRef]

26. Figley, J.; Sun, X.; Mylavarapu, S.K.; Hajek, B. Numerical study on thermal hydraulic performance of a printed circuit heat exchanger. Prog. Nucl. Energy 2013, 68, 89-96. [CrossRef]

27. Aneesh, A.M.; Sharma, A.; Srivastava, A.; Vyas, K.N.; Chaudhuri, P. Thermal-hydraulic characteristics and performance of 3D straight channel based printed circuit heat exchanger. Appl. Therm. Eng. 2016, 98, 474-482. [CrossRef]

28. Hamid, H.K.; Aneesh, A.M.; Autl, S.; Chaudhuri, P. Thermal hydraulic characteristics and performance of 3D wavy channel based printed circuit heat exchanger. Appl. Therm. Eng. 2015, 87, 519-528.

29. Ngo, T.L.; Kato, Y.; Nikitin, K.; Tsuzuki, N. New printed circuit heat exchanger with S-shaped fins for hot water supplier. Exp. Therm. Fluid Sci. 2006, 30, 811-819. [CrossRef]

30. Kim, D.E.; Kim, M.H.; Cha, J.E.; Kim, S.O. Numerical investigation on thermal-hydraulic performance of new printed circuit heat exchanger model. Nucl. Eng. Des. 2008, 238, 3269-3276. [CrossRef]

31. Xu, X.; Ma, T.; Li, L.; Zeng, M.; Chen, Y.; Huang, Y.; Wang, Q. Optimization of fin arrangement and channel configuration in an airfoil fin PCHE for supercritical $\mathrm{CO}_{2}$ cycle. Appl. Therm. Eng. 2014, 113, 867-875. [CrossRef]

32. Han, C.-L.; Ren, J.-J.; Dong, W.-P.; Bi, M.-S. Numerical investigation of supercritical LNG convective heat transfer in a horizontal serpentine tube. Cryogenics 2016, 78, 1-13. [CrossRef]

33. Bae, Y.Y. A new formulation of variable turbulent prandtl number for heat transfer to supercritical fluids. Int. J. Heat Mass Transf. 2016, 92, 792-806. [CrossRef]

34. Jeon, S.; Baik, Y.; Byon, C.; Kim, W. Thermal performance of heterogeneous PCHE for supercritical $\mathrm{CO}_{2}$ energy cycle. Int. J. Heat Mass Transf. 2016, 102, 867-876. [CrossRef]

35. Kruizenga, A.; Anderson, M.; Fatima, R.; Corradini, M.; Towne, A.; Ranjan, D. Heat transfer of supercritical carbon dioxide in printed circuit heat exchanger geometries. J. Therm. Sci. Eng. Appl. 2011, 3, 1-8. [CrossRef]

36. Kim, T.H.; Kwon, J.G.; Yoon, S.H.; Park, H.S.; Kim, M.H.; Cha, J.E. Numerical analysis of air-foil shaped fin performance in printed circuit heat exchanger in a supercritical carbon dioxide power cycle. Nucl. Eng. Des. 2015, 288, 110-118. [CrossRef]

37. Zhao, Z.; Zhang, X.; Zhao, K.; Jiang, P.; Chen, Y. Numerical investigation on heat transfer and flow characteristics of supercritical nitrogen in a straight channel of printed circuit heat exchanger. Appl. Therm. Eng. 2017, 126, 717-729. [CrossRef] 